\title{
Impact of the use of comfort devices on the exhaust toxic compounds from a modern PC car with spark ignition engine
}

ARTICLE INFO

Received: 13 August 202

Revised: 30 August 2021

Accepted: 14 September 2021

Available online: 13 October 2021
The use of comfort systems, the number of which in vehicles is constantly increasing, has a direct impact on fuel consumption and engine load. As part of the article, the vehicle's drive in real operating conditions was analyzed in terms of the emission of toxic compounds. The tests were carried out without and with the systems turned on, using the PEMS apparatus, where road emissions of carbon dioxide, carbon monoxide, hydrocarbons, nitrogen oxides and solid particles were measured in terms of mass, number and size distribution of diameters. The track was driven four times with different setting of the powertrain of examined car. The differences concerned the number of comfort systems in the vehicle and the mode of operation of the combustion engine.

Key words: exhaust emission, RDE, combustion engine, comfort devices

This is an open access article under the CC BY license (http://creativecommons.org/licenses/BY/4.0/)

\section{Introduction}

With the advancement in the automotive field, there is an increase in the number of amenities found in vehicles and affecting the comfort of passengers' travel. They are associated with increasing the weight of the vehicle, which translates into fuel consumption and the emission of toxic components. Mass directly influences the resistance to motion by increasing the inertia, and also, to a lesser degree, the rolling resistance $[7,9,10,13]$. Air resistance may be influenced by external elements related to the stylistic versions, usually increasing the frontal area of the vehicle or increasing the frontal drag of the vehicle. The number of amenities is particularly high in luxury vehicles, often doubling the original purchase price. The assembled device needs electricity to power it, which increases the load on the internal combustion engine by taking power from the crankshaft and converting the mechanical work into the electric energy in the alternator $[1,5,8]$. It is often associated with the use of starter batteries with increased capacity or increasing their number. As part of the approval tests, their use is not measured for fuel consumption and the emission of toxic components into the atmosphere [11]. An example of a comfort system is the air conditioning system, which in most vehicles requires the engine to be running, preventing the start / stop system from working. Operation may also be limited with other systems turned on when the instantaneous power consumed by the vehicle is significant. When analyzing the equipment of vehicles, a transfer of technology to lower-class vehicles is observed, and currently, in the B segment, an optional 360degree camera or active cruise control is observed [10].

Based on the work carried out in recent years, it was found that the qualitative and quantitative measurements of exhaust gases from internal combustion engines performed in laboratory conditions significantly differ from the actual emissivity of vehicles of a given category. It has been proved by various research institutions in Poland and abroad [3-6, 8, $9,13,14]$. Therefore, continuous efforts are being made to develop detailed and universal methods of assessing pollutant emissions in road conditions, generally classified as RDE (Real Driving Emissions). The development and miniaturization of measuring equipment belonging to the PEMS group (Portable Emission Measurement System), which has been progressing in recent years, allows for more and more precise tests of the environmental performance of vehicles in real operating conditions. From the moment when the Euro $6 \mathrm{c}$ standard came into force in 2017, it became necessary to perform road measurements in the field of compliance control of PC class vehicles in operation [2, 4]. It is currently the best method of researching the real impact of vehicle operation on the surrounding environment.

As part of the article, a road test of the vehicle was carried out in various driving modes and with the comfort systems turned on and off. The tested vehicle was equipped with PEMS equipment connected to the exhaust system and the emission of toxic components and carbon dioxide was measured, which also allowed the measurement of fuel consumption.

\section{Research methodology}

\subsection{Research objects}

The tested vehicle was equipped with a petrol engine with a displacement of $1.984 \mathrm{dm}^{3}$, power of $185 \mathrm{~kW}$ and a maximum torque is $370 \mathrm{Nm}$ (Table 1). The engine is a common unit in the VAG group with four cylinders and longitudinal position [10].

Table 1. Data of the tested vehicles engine [10]

\begin{tabular}{|l|c|}
\hline Parameter & Value \\
\hline $\begin{array}{l}\text { Number and arrangement of } \\
\text { cylinders and valves, engine type }\end{array}$ & $\begin{array}{c}\text { 4-cylinder, 4 valves per cylinder, } \\
\text { spark ignition, inline cylinders }\end{array}$ \\
\hline Fuel injection system & Direct injection \\
\hline Displacement & $1.984 \mathrm{dm}^{3}$ \\
\hline Maximum power & $185 \mathrm{~kW}$ at $5000-6800 \mathrm{rpm}$ \\
\hline Maximum torque & $370 \mathrm{Nm}$ at $1500-4500 \mathrm{rpm}$ \\
\hline Compression Ratio & $9.6: 1$ \\
\hline Aftertreatment systems & Double three way catalysts \\
\hline Turbocharging & $\begin{array}{c}\text { Turbocharger with VGT, inter- } \\
\text { cooled }\end{array}$ \\
\hline
\end{tabular}


The tested vehicle had a curb weight of $1920 \mathrm{~kg}$, during the tests it was loaded with the test equipment and two passengers, which translates into about $400 \mathrm{~kg}$ of additional weight (Fig. 1). Before the tests, the vehicle's mileage was $4,400 \mathrm{~km}$. Before the tests, the technical condition of the vehicle was checked and showed no inaccuracies.

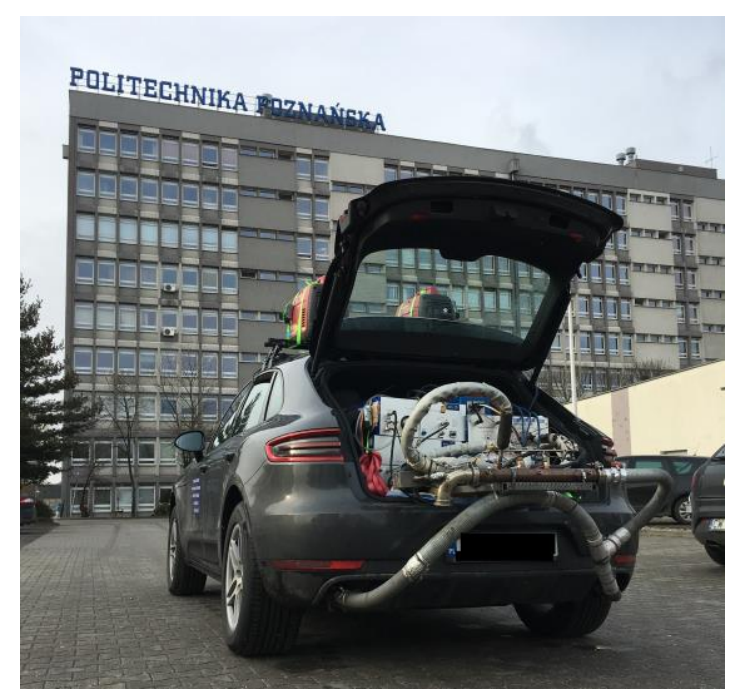

Fig. 1. The tested vehicle with PEMS apparatus

The comfort devices that were in the tested vehicle and that were turned on during passes 3 and 4 were: mirror heating, rear window heating, front and rear seat heating, front seat ventilation, sound system turned on at $80 \%$ of maximum power, air conditioning in auto mode set to a temperature of 21 degrees

\subsection{Used apparatus}

The equipment from the PEMS group was used for the measurements. It is a set of analyzers that analyze the exhaust gas sample taken from the exhaust system for the presence of harmful components in the form of: carbon dioxide and monoxide, nitrogen oxides, hydrocarbons and mass and number of emitted particles. For such a comprehensive assessment of the emissivity, 3 different SEMTECH DS analyzers were used (Fig. 2a). Particularly important in the case of modern petrol direct injection petrol engines is the assessment of particulate matter emissions. High-pressure fuel injection improves its atomization and facilitates the generation of a large amount of power from the same displacement volume, however, the lack of fuel evaporation associated with a shorter time that in the case of MPI (Multi Point Injection) systems it leads to weight reduction (PM), but increases the number of particles (PN). Therefore, the mass and particle size distribution tested by the EEPS instrument will also be analyzed (Fig. 2b and 2c). In this family of engines, emission is now reduced by a particulate filter in the exhaust system, while older designs used the second MPI injection system (the engine had 2 injectors per cylinder, direct and indirect) [10].

The technical data, where the range of tested parameters is listed, are listed in Table 2. The exhaust gas flow meter with a diameter of 2 inches was tightly connected to the exhaust system of the vehicle, which was adapted to the flow of exhaust gases from a turbocharged engine with a displacement volume of 1.5 to $2.5 \mathrm{dm}^{3}$. The information from the flow meter on the instantaneous flue gas mass flow allowed to determine the mass emission and the number of time periods during road tests

The route used for the study was located in the center of the city of Poznań (Fig. 3). It is characterized by different speed limits and well reflects the conditions of vehicles driving in the urban agglomeration. There are numerous infrastructure elements on it, such as several lanes and intersections with traffic lights. All tests, except for the cold start, were performed twice and the given result is the arithmetic mean of the obtained results. The length of the route was $11.04 \mathrm{~km}$.

a)

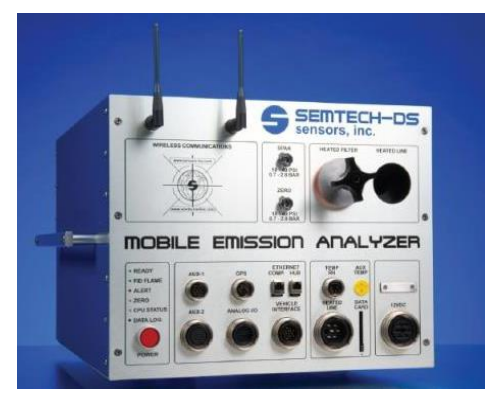

b)

c)
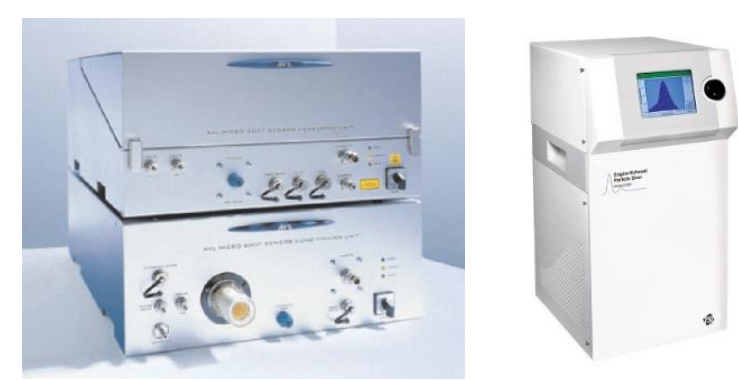

Fig. 2. View of the apparatus used in the research: a) SEMTECH DS analyzer, b) AVL MSS, c) EEPS TSI 3090 [12]

Table 2. Measurement range of used apparatus [12]

\begin{tabular}{|c|c|c|}
\hline \multicolumn{3}{|l|}{ Central Unit } \\
\hline $\begin{array}{l}\text { Examined } \\
\text { compound }\end{array}$ & Range & Accuracy $[\%]$ \\
\hline THC [ppm] & $0-40000$ & \pm 2 \\
\hline $\mathrm{CO}[\%]$ & $0-8$ & \multirow{3}{*}{ \pm 3} \\
\hline $\mathrm{CO}_{2}[\%]$ & $0-20$ & \\
\hline $\mathrm{HC}$ [ppm] & $0-4000$ & \\
\hline NO [ppm] & $0-3000$ & \pm 2 \\
\hline $\mathrm{PM}\left[\mathrm{mg} / \mathrm{m}^{3}\right]$ & $0,005-50$ & \pm 1 \\
\hline $\mathrm{PN}[\mathrm{nm}]$ & $5.6-560$ & \pm 1 \\
\hline \multicolumn{3}{|c|}{ Exhaust flow meter } \\
\hline Diameter & Flow measurement accuracy & Time response [s] \\
\hline $2 \mathrm{inch} / 51 \mathrm{~mm}$ & $\pm 2.5 \%$ & $\mathrm{~T}_{90}<1 \mathrm{~s}$ \\
\hline Vehicle type & \multicolumn{2}{|l|}{ Protocols } \\
\hline PC and LDV & \multicolumn{2}{|c|}{$\begin{array}{l}\text { SAE-J1850 PWM, SAE-J1850 VPW, ISO- } \\
\text { 9141-2, ISO-14230 (KWP-2000), ISO-15765 } \\
\text { (CAN), ISO-11898 (CAN) }\end{array}$} \\
\hline
\end{tabular}


The trip was planned in four configurations, i.e. test after a cold start, drive with a warmed-up engine vehicle, drive with a vehicle with switched on comfort receivers, drive with a warm engine and comfort systems in sport mode. Due to the lack of influence on the direct reproducibility of the tests, tests were carried out with all possible comfort systems as a reference from the assessment of their impact on the emissivity of the vehicle.

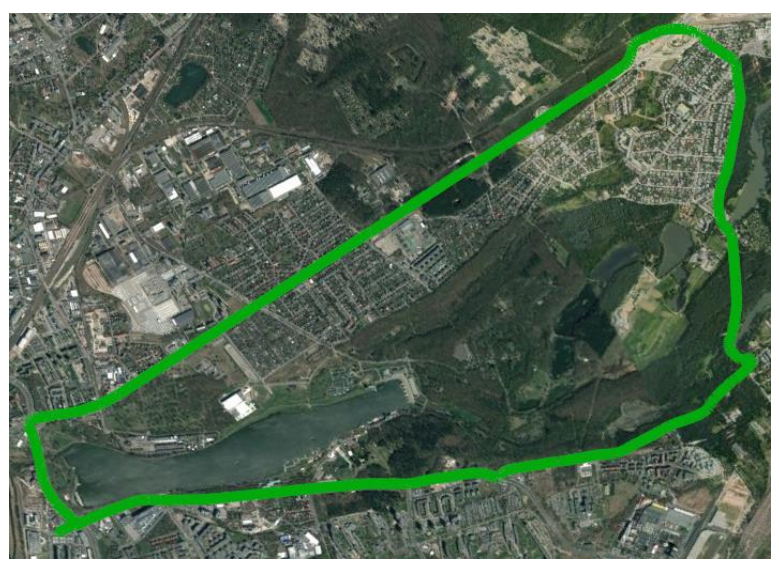

Fig. 3. View of the route used for testing [source: Google maps]

\section{Results}

Discussing the results at the beginning, the results concerning the test run in terms of speed, acceleration, rotational speed and load will be presented (Table 3 ).

Table 3. Parameters obtained during different cycles

\begin{tabular}{|l|c|c|c|c|}
\hline Cycle/parameter & $\begin{array}{c}\text { cold } \\
(1)\end{array}$ & $\begin{array}{c}\text { warm } \\
(2)\end{array}$ & $\begin{array}{c}\text { warm with } \\
\text { devices (3) }\end{array}$ & $\begin{array}{c}\text { sport with } \\
\text { devices (4) }\end{array}$ \\
\hline $\begin{array}{l}\text { Average speed } \\
{[\mathrm{km} / \mathrm{h}]}\end{array}$ & 29.7 & 28.9 & 29.4 & 28.3 \\
\hline $\begin{array}{l}\text { Average accelera- } \\
\text { tion [m/s }{ }^{2} \text { ] }\end{array}$ & 0.33 & 0.34 & 0.39 & 0.42 \\
\hline $\begin{array}{l}\text { Average engine } \\
\text { speed [rpm] }\end{array}$ & 1223 & 1161 & 1231 & 1624 \\
\hline $\begin{array}{l}\text { Average engine } \\
\text { load [\%] }\end{array}$ & 23.7 & 19.0 & 20.3 & 24.8 \\
\hline
\end{tabular}

All tracks were similar, which confirms the marginal impact of possible congestion on vehicle movement. The average speeds were very similar, as was the acceleration, which was the highest in the sport mode and was caused by an increased response to pressing the accelerator pedal. The differences are also visible in the engine speed. They are very similar for driving without and with comfort systems after warming up the engine. The obtained values were higher when the engine was cold and in sport mode, which also agrees with the theoretical assumptions. In these cycles, the engine speed and load were significantly increased. Similar parameters of the trip allow for the comparison of the emissivity of toxic compounds in the tested cycles.

The first component analyzed is carbon dioxide, which is directly related to the fuel consumption of the internal combustion engine. During the 1st cycle, when the engine is cold, fuel consumption is clearly higher than in cycle 2 , where the engine is at operating temperature, and even more than in cycle 3, where comfort systems were used.
The use of the sport mode greatly increased the fuel consumption (Fig. 4).

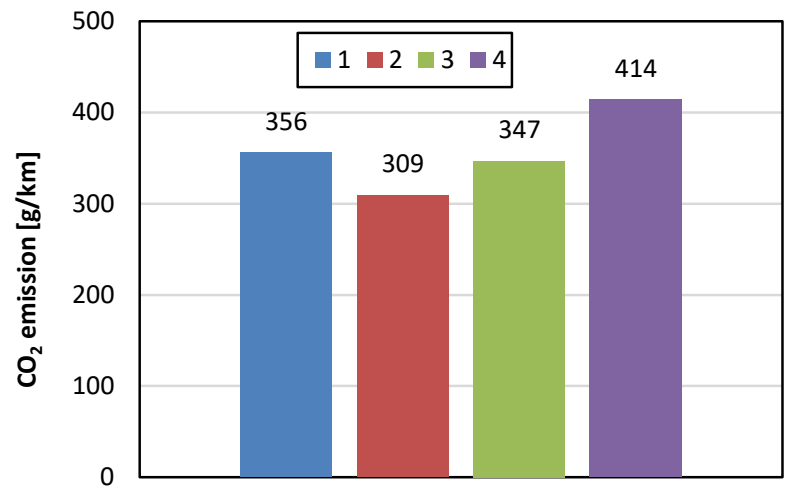

Fig. 4. $\mathrm{CO}_{2}$ emissions during tests

The analysis of the emission of toxic compounds to gaseous compounds was started, the emission of carbon monoxide, i.e. a compound formed mainly as a result of local and global oxygen deficiency in the fuel-air mixture (Fig. 5). the obtained results will be referenced to the standard, but direct comparison will not be possible due to the different test conditions from the approval or cycle run in accordance with RDE. Limits were taken from the homologation of Euro 6c PC vehicles [4].

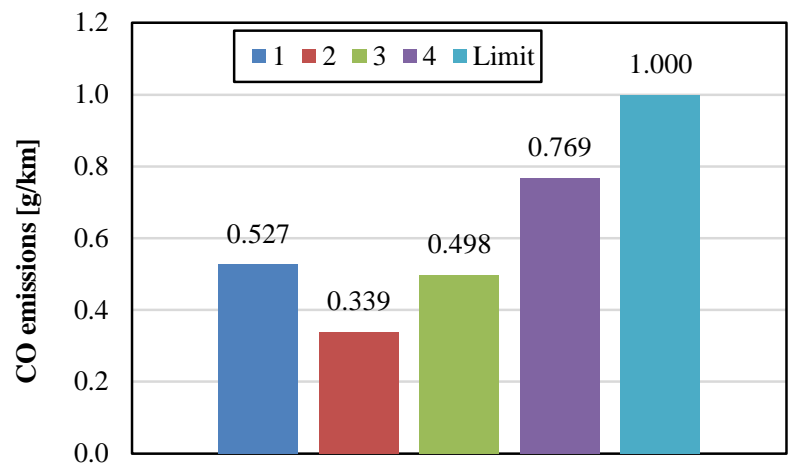

Fig. 5. CO emissions during tests

Increased $\mathrm{CO}$ emissions are typical for a cold engine, where the mixture is enriched and the lower temperature makes it difficult to evaporate the fuel. Warming up the engine significantly reduces carbon monoxide emissions (cycle 2), which remains below the cold engine value also for cycle 3. Sport mode significantly increases carbon monoxide emissions, most likely by increasing the torque and power output. None of the trips even comes close to the limit contained in the standards, which is confirmed by the authors' previous research in the study of carbon monoxide emissions $[7,8,13]$. The next analysis concerned the emission of hydrocarbons (Fig. 6)

The emission of hydrocarbons (in the case of the SEMTECH analyzer, calculated as the emission of propane) is very similar to that of carbon monoxide, which is also confirmed by theoretical assumptions. In this case, however, the highest value occurs for a cold start of the vehicle. The 
value is significantly reduced for the warm engine, but interestingly it is reduced by activating the comfort system, which was not the case with carbon monoxide. Switching on the sport mode, as in the first analyzed compound, significantly increases road emissions. Again, all results are below par, which also supports previous testing and proves the effectiveness of the aftertreatment systems and technologies used in modern SI engines. Another tested gas component was the emission of nitrogen oxides (Fig. 7).

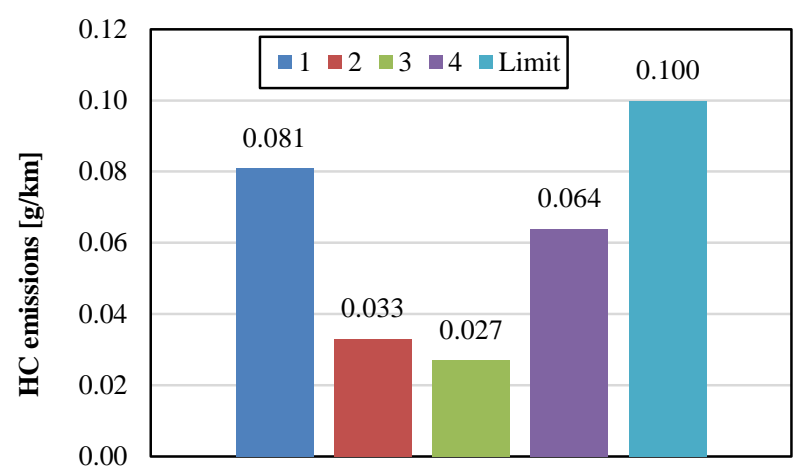

Fig. 6. HC emissions during tests

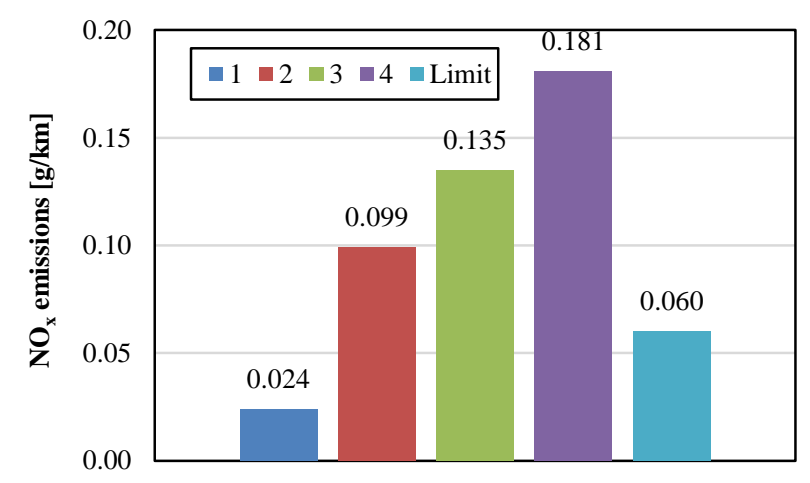

Fig. 7. $\mathrm{NO}_{\mathrm{x}}$ emissions during tests

The results of nitrogen oxides emission clearly match the theoretical assumptions, where their emission should increase in a hot engine and increase with increasing momentary loads. It is related to the increased temperature in the combustion chamber and the increased processes of combining oxygen with nitrogen contained in the air. The figure also shows the effect of the use of comfort modules on $\mathrm{NO}_{\mathrm{x}}$ emissions and the use of the sport mode. Comparing the mileage emission with the approval data, the obtained results are clearly greater for a warm engine. The discussed compounds concerned the gases contained in the exhaust gas. Further analysis will concern the emission of particulate matter (Fig. 8).

The first aspect considered was the mass of the particulates. It is the approximate mass of particles, mainly composed of soot, which is the cause of imperfections in the combustion process of the fuel in the chamber and the combustion of the engine oil. In this case, a cold engine, often running on a slightly enriched mixture and having, at least for part of the route, an underheated exhaust gas treatment system. The use of comfort systems almost triples their content, and the use of the sport mode increases it even more. It should be emphasized, however, that the obtained results are much lower than the approval limits and allow for conclusions about the environmental performance of the engine, which was not always found in other studies by the authors [2, 3]. Another analyzed index was the number of particles per kilometre (Fig. 9).

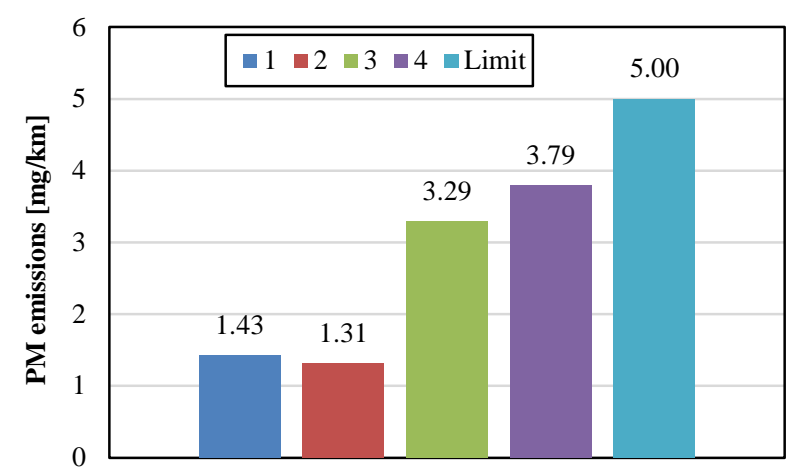

Fig. 8. PM emissions during tests

Particulate emissions in terms of numbers is an important aspect introduced in the limits for passenger vehicles in 2017 in the Euro 6c standard. Its introduction was related to the emission of nanoparticles caused by the use of direct gasoline injection. Nowadays, the advantages of this technology have practically dominated the market of engines in PC class vehicles [10]. The tests carried out as part of the test showed similar particle emissions in all test cycles. The lowest result was measured for the warm engine. The use of comfort systems increases their content by over $50 \%$, and the use of the sport mode does not increase their content as clearly as for PM. Considering the results obtained in relation to the engine warmed up as a percentage, the use of the comfort systems and the sport mode increases the content of all compounds, except for hydrocarbons (Table 4).

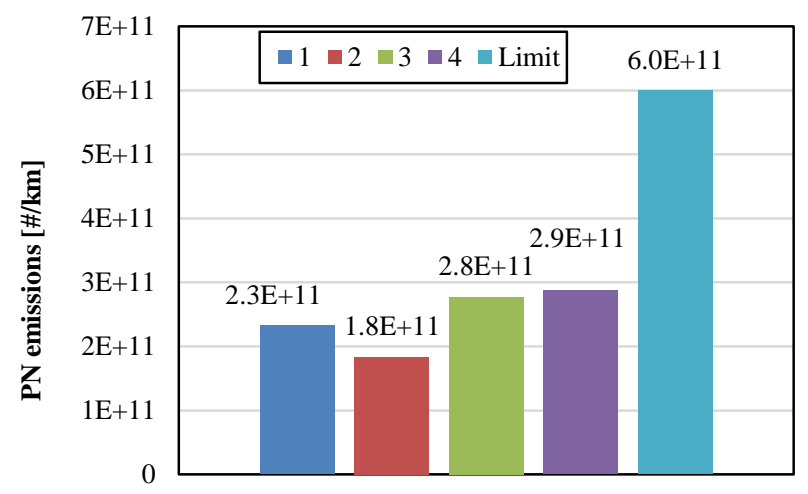

Fig. 9. PN emissions during tests

Taking the limit from the norm as $100 \%$ in the cycles obtained, lower values were obtained in all tested compounds, except for nitrogen oxides, where the increase was significant and exceeded three times the limits (Table 5). 
Table 4. Relative emission in cycles 3 and 4 in comparison of cycle 2

\begin{tabular}{|c|c|c|c|c|c|}
\hline Emission/cycle & $\mathrm{CO}$ & $\mathrm{HC}$ & $\mathrm{NO}_{\mathrm{x}}$ & $\mathrm{PM}$ & $\mathrm{PN}$ \\
\hline 2 & $100 \%$ & $100 \%$ & $100 \%$ & $100 \%$ & $100 \%$ \\
\hline 3 & $147 \%$ & $82 \%$ & $183 \%$ & $251 \%$ & $151 \%$ \\
\hline 4 & $227 \%$ & $194 \%$ & $136 \%$ & $290 \%$ & $156 \%$ \\
\hline
\end{tabular}

Table 5. Relative emission in all cycles in comparison of limits $($ limit $=100 \%)$

\begin{tabular}{|c|c|c|c|c|}
\hline Compound/cycle & 1 & 2 & 3 & 4 \\
\hline $\mathrm{CO}$ & $53 \%$ & $34 \%$ & $50 \%$ & $77 \%$ \\
\hline $\mathrm{HC}$ & $10 \%$ & $17 \%$ & $48 \%$ & $41 \%$ \\
\hline $\mathrm{NO}_{\mathrm{x}}$ & $40 \%$ & $165 \%$ & $225 \%$ & $302 \%$ \\
\hline $\mathrm{PM}$ & $29 \%$ & $26 \%$ & $66 \%$ & $76 \%$ \\
\hline $\mathrm{PN}$ & $39 \%$ & $31 \%$ & $47 \%$ & $49 \%$ \\
\hline
\end{tabular}

The last aspect considered was the dimensional distribution of the diameters of the solid particles. It allows to consider the number not only quantitatively, but also allows to examine whether particles of a characteristic size are emitted from the engine, especially the smallest particles that are particularly dangerous to life. The results are shown in Figs 10-13. For ease of comparison, the range of values on the $\mathrm{Y}$ axis has been adjusted to the highest value obtained for cycle 3 .

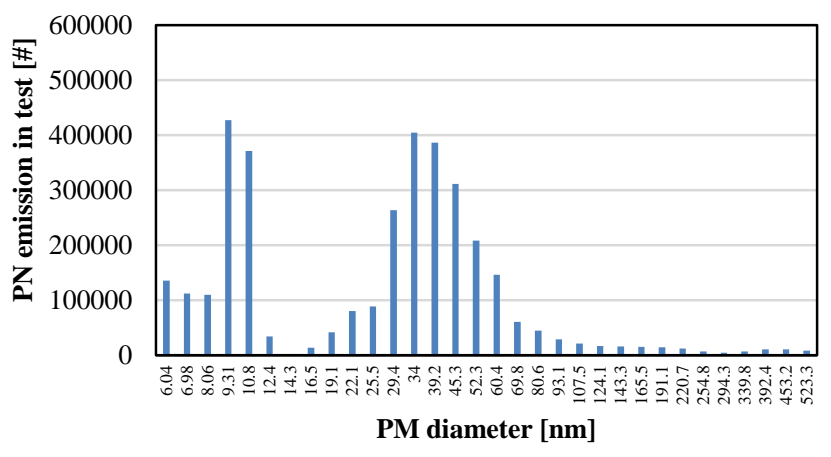

Fig. 10. PM diameter distribution during tests cycle no 1

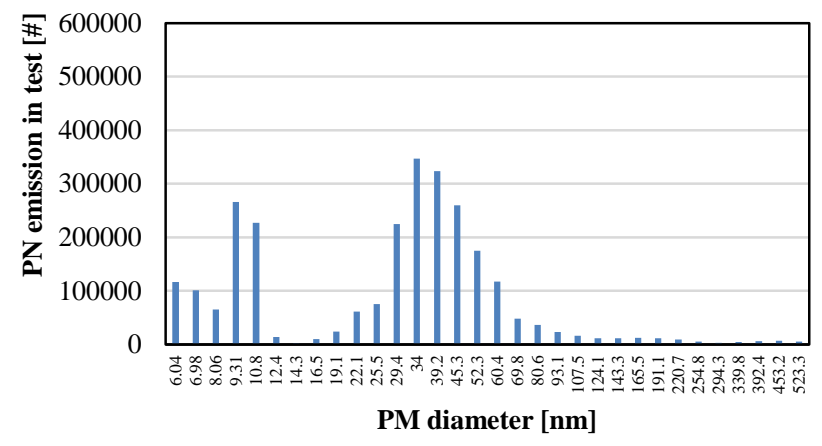

Fig. 11. PM diameter distribution during tests cycle no 2

In all the obtained cycles, very similar results were recorded for the distribution of diameters of $16 \mathrm{~nm}$ and larger. The obtained local maximum differs, which in all cases falls in the diameter of $34 \mathrm{~nm}$. The value obtained is only lower for cycle 2, where the engine was warmed up and unloaded with the comfort systems. Much greater differences concern the emission of nanoparticles, i.e. the range of $6-12 \mathrm{~nm}$. For cycles $1-3$, the ratio of individual measured diameters seems to be very similar, it runs up for passes No. where the channel ratio of 9.31 and 6.04 is greater than in the other passes. Ruthlessly analyzing the obtained results, pass 3 and 4 do not differ much from each other, but 2 and 3 are very different. It points to an almost twice increase in the emission of nanoparticles after the use of comfort systems. The result for the cold engine is also greater than for cycle 2, but lower than for cycle 3 and 4 . According to the authors, the increase in emissions measured in the exhaust manifold would be greater, but some of the particles are oxidized in the hot TWC.

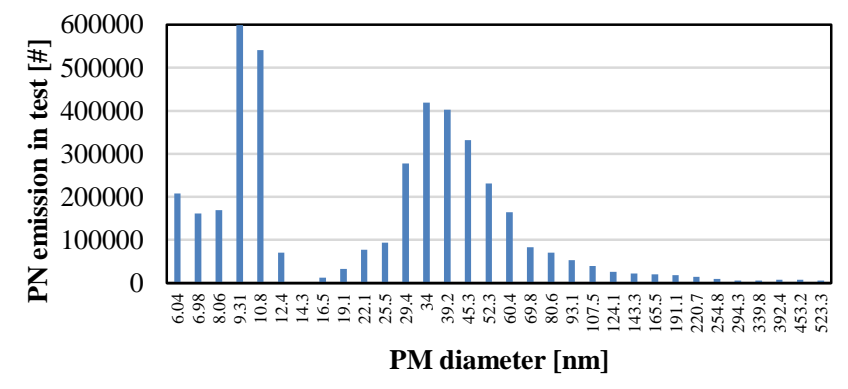

Fig. 12. PM diameter distribution during tests cycle no 3

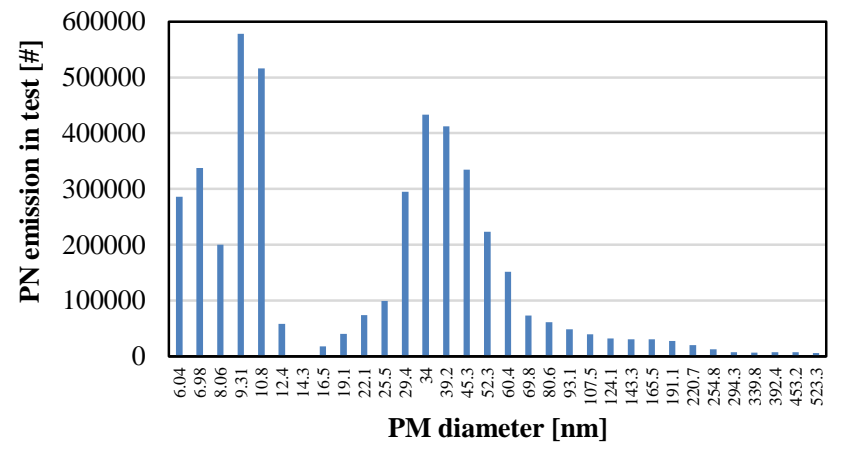

Fig. 13. PM diameter distribution during tests cycle no 4

The obtained results indicate an increase in the emissions of two compounds to reduce emissions, which are trying to be achieved by vehicle and engine manufacturers, i.e. nitrogen oxides and solid particles. The analysis also showed an increase in the emission of nanoparticles, the most dangerous for human life and health.

\section{Conclusion}

The article examines the emissions of a vehicle with a modern gasoline engine during real driving in the city center. The number of amenities in vehicles is constantly increasing, and the devices used are powered by the electricity generated by the engine, loading it. The impact of this load is not measured during approval tests, and such conditions occur in the actual operation of vehicles. The emission performance of gaseous components, apart from nitrogen oxides, is not significantly increased by the use of comfort systems. The increase took place in the field of nitrogen oxides and particulate matter, the emission of which is the biggest problem in currently produced vehicles 
with both spark ignition and compression ignition engines. The tested vehicle was characterized by relatively small dimensions and weight, in the future it is planned to extend the tests to higher segment vehicles.

\section{Acknowledgements}

The research was funded by European Union from European Regional Development Fund through the National
Centre for Research and Development (Narodowe Centrum Badań i Rozwoju) - research project within the Smart Growth Programme (contract No. POIR.04.01.02-00$0002 / 18)$.

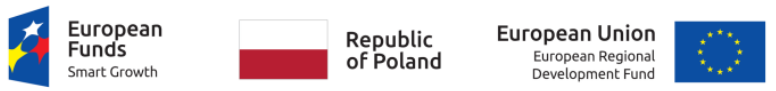

\section{Nomenclature}

DI direct injection

GPF gasoline particulate filter

MPI multi point injection

PC passenger cars

PEMS Portable Emissions Measurement System

PM particle mass
PN particle number

RDE Real Driving Emissions

SI spark ignition

TWC three way catalyst

VGT variable geometry turbine

\section{Bibliography}

[1] AIKAWA, K., JETTER, J.J. Impact of gasoline composition on particulate matter emissions from a direct-injection gasoline engine. Applicability of the particulate matter index. International Journal of Engine Research. 2014, 15, 298-306. https://doi.org/10.1177/1468087413481216

[2] AOYAGI, Y. Measurement of flame temperature and soot amount for effective $\mathrm{NO}_{\mathrm{x}}$ and $\mathrm{PM}$ reduction in a heavy duty diesel engine. Combustion Engines. 2019, 179(4), 32-39. https://doi.org/10.19206/CE-2019-405

[3] BRZEŻAŃSKI, M., RODAK, Ł. Influence of the method of creating a hydrogen-air mixture on the emission of nitrogen oxides in a spark-ignition engine. Combustion Engines. 2019, 178(3), 224-227.

https://doi.org/10.19206/CE-2019-339

[4] GIECHASKIEL, B., LAHDE, T., SUAREZ-BERTOA, R. et al. Particle number measurements in the European legislation and future JRC activities. Combustion Engines. 2018, 174(3), 3-16. https://doi.org/10.19206/CE-2018-301

[5] KURTYKA, K., PIELECHA, J. Cold start emissions from a gasoline engine in RDE tests at different ambient temperatures. Combustion Engines. 2020, 181(2), 24-30. https://doi.org/10.19206/CE-2020-204

[6] LIJEWSKI, P., FUĆ, P., MARKIEWICZ, F. et al. Problems of exhaust emissions testing from machines and mobile devices in real operating conditions. Combustion Engines. 2019, 179(4), 292-296.

https://doi.org/10.19206/CE-2019-449

Maciej Siedlecki, DEng. - Faculty of Civil and Transport Engineering, Poznan University of Technology.

e-mail: maciej.siedlecki@put.poznan.pl

Michał Dobrzyński, DEng. - Faculty of Civil and Transport Engineering, Poznan University of Technology.

e-mail: michal.dobrzyński@put.poznan.pl

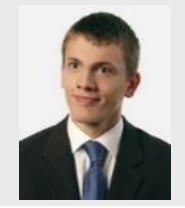

[7] MERKISZ, J., DOBRZYSKI, M., KUBIAK, K. An impact assessment of functional systems in vehicles on $\mathrm{CO}_{2}$ emissions and fuel consumption, MATEC Web of Conferences. 2017, 118, 00030.

https://doi.org/10.1051/matecconf/ 201711800030

[8] MERKISZ, J., PIELECHA, J. Observations from PEMS testing of combustion engines of different applications. Combustion Engines. 2018, 174(3), 40-55. https://doi.org/10.19206/CE-2018-305

[9] PIELECHA, J., KURTYKA, K., SKOBIEJ, K. The impact of vehicle dynamic parameters on the exhaust emissions in RDE tests. Combustion Engines. 2018, 175(4), 26-34. https://doi.org/10.19206/CE-2018-404

[10] Porsche and Nissan materials.

[11] RYMANIAK, Ł., DASZKIEWICZ, P., MERKISZ, J. et al. Methods of evaluating the exhaust emissions from driving vehicles. Combustion Engines. 2019, 179(4), 286-291. https://doi.org/10.19206/CE-2019-448

[12] Sensors Inc., AVL and TSI manuals.

[13] SIEDLECKI, M., MERKISZ, J., KUBIAK, K. et al. Impact of the use of comfort devices on the exhaust emission from a hybrid vehicle. Combustion Engines. 2019, 179(4), 250285. https://doi.org/10.19206/CE-2019-447

[14] WIŚNIOWSKI, P., GIS, M. Representativeness of emissions of toxic substances in bench tests reflecting the road traffic conditions of a vehicle. Combustion Engines. 2019, 177(2), 88-90. https://doi.org/10.19206/CE-2019-215

Prof. Jerzy Merkisz, DSc., DEng. - Faculty of Civil and Transport Engineering, Poznan University of Technology.

e-mail: jerzy.merkisz@put.poznan.pl
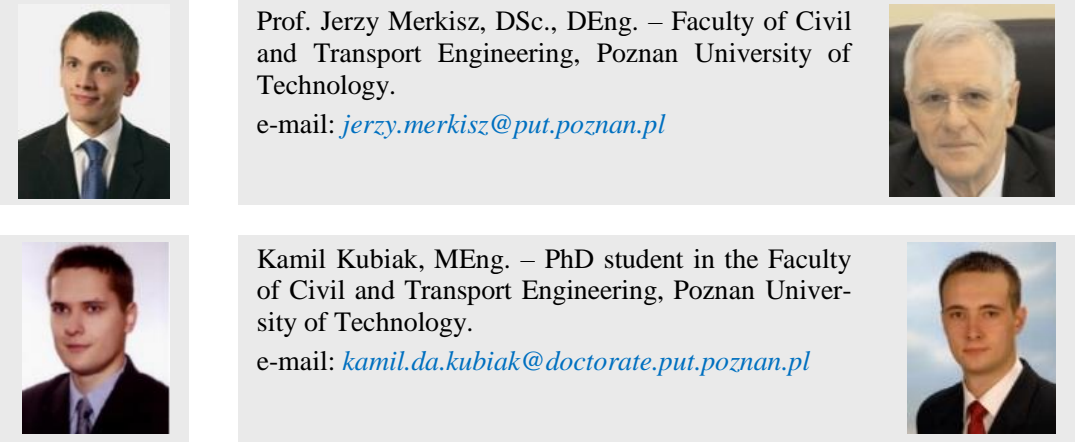

Kamil Kubiak, MEng. - PhD student in the Faculty of Civil and Transport Engineering, Poznan University of Technology.

e-mail: kamil.da.kubiak@doctorate.put.poznan.pl 